\title{
A promising start for Nature Clinical Practice Cardiovascular Medicine
}

\author{
Rachel Ashton and Valentin Fuster
}

Next month, Nature Clinical Practice Cardiovascular Medicine will celebrate its first anniversary. In the inaugural issue, we asked "why do we need yet another journal?" Certainly, a host of high-quality cardiovascular medicine publications are available, but we felt that a niche remained to be filled by a journal that presents information relevant to practice in a convenient, highly accessible format. We started the year full of hope for success; we will bring the $12^{\text {th }}$ month to a close well on the road to achieving it.

The aim from the outset has been to provide stimulating, authoritative content that expands the specialty and subspecialty knowledge of practicing physicians. We have been delighted over the past year to be able to do this by securing the authorship and peer-review services of some of the leading lights in the field, and it is a pleasure to acknowledge the overwhelming support of all our contributors and the Advisory Board in this new venture. With their help, we have now published more than 130 fully peer-reviewed articles across the Viewpoints, Practice Points, Reviews and Case Studies sections. The journal is now indexed in Index Medicus/MEDLINE, PubMed, EMBASE/ Excerpta Medica and ISI Web of Knowledge, among other sources. We have also launched a PDA service to bring all our content to physicians' fingertips.

As we have guided the journal through its first year, we have honed several features of the original concept to really make Nature Clinical Practice Cardiovascular Medicine stand out from the crowd. Part of our ethos is that all the content should be easily readable and digestible to help physicians keep up to date with the major developments in cardiovascular
"... it is a

pleasure to

acknowledge

the

overwhelming

support

of all our

contributors

in this new

venture."

$R$ Ashton is the

Editor and V Fuster

is the Editor-in-

Chief of Nature

Clinical Practice

Cardiovascular

Medicine.

\section{Competing interests}

The authors declared they

have no competing interests

www.nature.com/clinicalpractice doi:10.1038/ncpcardio0329 medicine, even with all the pressure on their time. We have designed the articles to be concise. We take much care when planning what to cover in our articles, working with authors to keep the scope of the discussion focused, even in the review articles. This method ensures that we include only the most-relevant information, that it is of the highest quality and is fully supported by pertinent references.

To keep the content relevant, we also believe that timeliness is very important. Through the Practice Point section particularly we have put into context some of the latest influential studies reported in other journals. In the Reviews section, we have kept up with the most quickly advancing areas, such as cell therapy and imaging technology, and have been able to summarize the major points of fast-changing topics, such as the cardiovascular risks of cyclo-oxygenase 2 inhibitors, at opportune moments.

To move Nature Clinical Practice Cardiovascular Medicine forward through the next 12 months and beyond, we aim not merely to continue in the vein we have established so far, but to evolve the journal. We believe wholeheartedly that we have much, much more to offer our readers. To aid this process, readers may send us feedback and comments on any issue to do with the journal via the website at www.nature.com/ncpcardio.

We said in the beginning that we would provide an invaluable tool to academic and practicing doctors in what promised to be the premier cardiovascular journal. We are a step closer to that goal with what we have achieved so far. With the support of our readers, authors and peer-reviewers, we are sure we can go much further. 